\title{
Deep brain stimulation in patients on chronic antiplatelet or anticoagulation treatment
}

\author{
Joachim Runge ${ }^{1}$. Luisa Cassini Ascencao ${ }^{1}$. Christian Blahak ${ }^{2,3}$. Thomas M. Kinfe ${ }^{4}$. Christoph Schrader ${ }^{5}$. \\ Marc E. Wolf ${ }^{2,6} \cdot$ Assel Saryyeva ${ }^{1} \cdot$ Joachim K. Krauss ${ }^{1,7}$
}

Received: 16 March 2021 / Accepted: 28 June 2021 / Published online: 3 August 2021

(c) The Author(s) 2021

\begin{abstract}
Background In the aging society, many patients with movement disorders, pain syndromes, or psychiatric disorders who are candidates for deep brain stimulation (DBS) surgery suffer also from cardiovascular co-morbidities that require chronic antiplatelet or anticoagulation treatment. Because of a presumed increased risk of intracranial hemorrhage during or after surgery and limited knowledge about perioperative management, chronic antiplatelet or anticoagulation treatment often has been considered a relative contraindication for DBS. Here, we evaluate whether or not there is an increased risk for intracranial hemorrhage or thromboembolic complications in patients on chronic treatment (paused for surgery or bridged with subcutaneous heparin) as compared to those without.

Methods Out of a series of 465 patients undergoing functional stereotactic neurosurgery, 34 patients were identified who were on chronic treatment before and after receiving DBS. In patients with antiplatelet treatment, medication was stopped in the perioperative period. In patients with vitamin K antagonists or novel oral anticoagulants (NOACs), heparin was used for bridging. All patients had postoperative stereotactic CT scans, and were followed up for 1 year after surgery.

Results In patients on chronic antiplatelet or anticoagulation treatment, intracranial hemorrhage occurred in $2 / 34$ (5.9\%) DBS surgeries, whereas the rate of intracranial hemorrhage was $15 / 431(3.5 \%)$ in those without, which was statistically not significant. Implantable pulse generator pocket hematomas were seen in 2/34 (5.9\%) surgeries in patients on chronic treatment and in 4/426 (0.9\%) without. There were only 2 instances of thromboembolic complications which both occurred in patients without chronic treatment. There were no hemorrhagic complications during follow-up for 1 year.

Conclusions DBS surgery in patients on chronic antiplatelet or anticoagulation treatment is feasible. Also, there was no increased risk of hemorrhage in the first year of follow-up after DBS surgery. Appropriate patient selection and standardized perioperative management are necessary to reduce the risk of intracranial hemorrhage and thromboembolic complications.
\end{abstract}

Keywords Anticoagulation · Antiplatelet $\cdot$ Deep brain stimulation $\cdot$ Functional neurosurgery $\cdot$ NOAC $\cdot$ Vitamin K antagonist

Joachim Runge and Luisa Cassini Ascencao contributed equally to this work.

This article is part of the Topical Collection on Functional Neurosurgery-Other

Joachim Runge

runge.joachim@mh-hannover.de

1 Department of Neurosurgery, Hannover Medical School, Carl-Neuberg-Straße 1, 30625 Hannover, Germany

2 Department of Neurosurgery, Universitätsmedizin Mannheim, Medical Faculty Mannheim, University of Heidelberg, Heidelberg, Germany

3 Department of Neurology, Ortenau Klinikum Lahr-Ettenheim, Lahr, Germany

\author{
Abbreviations \\ DBS Deep brain stimulation \\ NOACs Novel oral anticoagulants \\ IPG Implantable pulse generators
}

4 Department of Neurosurgery, Division of Functional Neurosurgery and Stereotaxy, Friedrich-Alexander University, Erlangen-Nürnberg, Erlangen, Germany

5 Department of Neurology, Hannover Medical School, Hannover, Germany

6 Department of Neurology, Katharinenhospital Stuttgart, Stuttgart, Germany

7 Center of Systems Neuroscience, Hannover, Germany 


$\begin{array}{ll}\text { PD } & \text { Parkinson disease } \\ \text { INR } & \text { International normalization ratio } \\ \text { PTT } & \text { Partial thromboplastin time } \\ \text { GPi } & \text { Globus pallidus internus } \\ \text { STN } & \text { Subthalamic nucleus } \\ \text { ET } & \text { Essential tremor } \\ \text { Vim } & \text { Ventral intermediate nucleus } \\ \text { CM-Pf } & \text { Centromedian-parafascicular complex } \\ \text { VPL } & \text { Ventral posterior lateral nucleus }\end{array}$

\section{Introduction}

The management of chronic antiplatelet or anticoagulation treatment is a common problem in patients considered for elective surgery. Perioperative discontinuation of antiplatelet or anticoagulation treatment may increase the risk of thromboembolic and cardiovascular events [3, 8, 13] while continued treatment increases the risk of hemorrhage [23]. Particularly, in cerebral surgery, the risk of intracranial hemorrhage is significantly increased, making antiplatelet or anticoagulation treatment a relative contraindication for neurosurgical procedures [34]. Also, the timing of discontinuation of medication, the perioperative bridging of anticoagulation, and its resumption after neurosurgery are a matter of ongoing debate [21, 34].

Deep brain stimulation (DBS) with chronically implanted electrodes and implantable pulse generators (IPG) has become a common and widely accepted therapy for various movement disorders, chronic pain, and psychiatric disorders $[14,17,19,22]$. Intracranial hemorrhage has been considered the most serious complication of DBS resulting in prolonged hospitalization, additional surgery, or permanent disability [20, 24, 29, 35]. While the frequency of asymptomatic hemorrhage ranges between 0.2 and $3.7 \%$, symptomatic hemorrhage occurs in $0.0-1.6 \%$ of patients with an overall mortality of $0.0-0.7 \%[11,38]$. Therefore, there is an urgent clinical need to prevent hemorrhage and to develop strategies for its avoidance.

Perioperative management is crucial for an elective procedure such as DBS. There is an increasing number of elderly patients with movement disorders or chronic pain syndromes who often suffer also from co-morbidities such as cardiovascular diseases which require lifelong antiplatelet or anticoagulation treatment [4].

In general, any form of chronic anticoagulation treatment has been considered a relative contraindication for DBS [4, 11]. The question, however, arises whether an established therapy such as DBS can be denied to these groups of patients. While many neurosurgeons worldwide perform DBS in patients with chronic antiplatelet or anticoagulation treatment, there is very limited published data addressing this problem $[4,25,31,33,36]$. Furthermore, there are different drugs for antiplatelet or anticoagulation treatment, each with distinctive mechanisms and duration of action.

Here, we report our experience on the perioperative management of chronic antiplatelet or anticoagulation treatment in a series of 34 DBS patients and focus on the occurrence of hemorrhagic or thromboembolic complications with a follow-up for 1 year.

\section{Materials and methods}

Between 2005 and 2018, 465 patients underwent functional stereotactic surgeries (DBS or radiofrequency lesioning) at Hannover Medical School, performed or supervised by the senior neurosurgeon (JKK). Indications were Parkinson's disease (PD), dystonia, tremor, chronic pain syndromes, and psychiatric disorders. Results on clinical outcome and neurophysiology have been published in detail elsewhere [7, 9, 27, 28, 32].

Inclusion criteria for the present study were (1) chronic antiplatelet or anticoagulation treatment prior to and continued after functional stereotactic surgery; (2) implantation of DBS electrodes and an implantable pulse generator (IPG) for chronic stimulation. Exclusion criteria were transient test stimulation only via the DBS electrodes or radiofrequency lesioning.

For the present study, a retrospective analysis of the prospectively collected data was performed. All hemorrhagic and thromboembolic complications (intracranial and IPG pocket hematoma) were recorded during the perioperative period and for follow-up for 1 year. The patients were divided into three subgroups based on therapy regimes: antiplatelet drugs, vitamin $\mathrm{K}$ antagonists, and novel oral anticoagulants (NOACs). The subgroups were compared to each other and with the larger collective of patients without chronic antiplatelet or anticoagulation medication.

All patients with antiplatelet or anticoagulation treatment were first seen as outpatients. Patients were instructed to consult their general physician to assess their individual risk of transient withdrawal of treatment. Thereafter, they were instructed routinely how to proceed with treatment prior to the planned day of admission based on the different therapy regimes. Preoperative standard examination included an extensive anesthesiological work-up. Antiplatelet medication, such as aspirin or clopidogrel, regardless if used for primary or secondary prophylaxis, was stopped 7-10 days preoperatively. No bridging with high or low molecular weight heparin was initiated in these cases. The patients with vitamin $\mathrm{K}$ antagonists were instructed to stop medication and start bridging with subcutaneous low molecular weight heparin as soon as the international normalization ratio (INR) was below 2 before being admitted for surgery [23]. Patients 
with NOACs discontinued medication 2-3 days before surgery (approximately 5 half-lives) and bridged also with subcutaneous low molecular weight heparin. All patients gave informed consent to the planned procedure.

On the day of admission, coagulation lab values were determined including the INR and partial thromboplastin time (PTT). It was considered safe to perform DBS surgery with an INR $<1.2$ (Quick $>80 \%$ ), a PTT $<36$ s, and a platelet count $>100.000$. When used for bridging, fractionated heparin was stopped $>12 \mathrm{~h}$ prior to surgery, and continued $24 \mathrm{~h}$ after surgery.

The operative technique has been described in detail elsewhere [1, 9, 30]. Preoperative MRI scans were obtained in all patients. A Riechert-Mundinger stereotactic frame with the Zamorano-Duchovny semi-arc was used in all surgeries. Target and trajectory planning was performed on different work stations (Medtronic ${ }^{\circledR}$ StealthStation 3, StealthStation 7, Brainlab $\left.{ }^{\circledR}\right)$ based on stereotactic 1.25mm axial CT scans.

Patients were operated under local anesthesia via precoronal burr holes. Transventricular approaches were accepted. When the globus pallidus internus (GPi) or the subthalamic nucleus (STN) were targeted, microelectrode recording was performed as described previously $[1,30]$. Intraoperative macrostimulation was achieved via the DBS electrodes to determine thresholds for effects and side effects. Standard quadripolar DBS electrodes were implanted via a guiding-cannula (Medtronic ${ }^{\circledR}$ 3387 or 3389; Boston Scientific ${ }^{\circledR}$ Vercise DBS Lead or Versice Cartesia Directional Lead) and used for chronic stimulation.
Stereotactic CTs were obtained immediately postoperatively in all patients to verify the electrode position and to detect any intracranial complications. The IPG was implanted under general anesthesia directly thereafter during the same operative session or within the following days.

Subcutaneous weight-adapted fractionated heparin was commenced $24 \mathrm{~h}$ postoperatively in all patients of the three subgroups for prophylaxis of thrombosis and to continue bridging. Intravenous antibiotics were administered for $48 \mathrm{~h}$. Programming of the IPG was started after monopolar review and impedance measurements on the day after implantation of the IPG. Stitches were removed between days 10 and 12 after surgery. Bridging therapy with heparin was continued for 2 weeks after surgery. Thereafter, permanent antiplatelet or anticoagulation treatment was resumed and adjusted by the patients' general physicians.

The Ethical Commission of Hannover Medical School indicated that no formal approval was needed for the present study.

For statistical analysis, the chi-square test (Fischer's exact test) was used. Statistical significance was determined as $p<0.05$.

\section{Results}

Out of the total cohort of 465 patients, 34 patients (7.3\%) were identified who were under chronic antiplatelet or anticoagulation treatment according to our inclusion and exclusion criteria. There were 24 men and 10 women, and mean age at surgery was 68.1 years (range \pm 11.6 ). Out of these 34,18 were on antiplatelet therapy, 13 had vitamin
Table 1 Demographic data, diagnoses, and DBS targets in 34 patients

\begin{tabular}{llll}
\hline & Antiplatelet drugs & Vitamin K antagonists & NOACs \\
\hline Total & 18 & 13 & 3 \\
Gender & & & \\
$\quad$ Male & 12 & 10 & 1 \\
$\quad$ Female & 6 & 3 & $76 \pm 2.8$ \\
Age (years) & $67.1 \pm 10.3$ & $67.6 \pm 13.6$ & 1 \\
Diagnosis & & & 2 \\
PD & 7 & 1 & \\
ET & 5 & 10 & \\
Dystonia & 5 & 2 & 3 \\
Pain & 1 & & \\
DBS target & & 1 & \\
STN & 4 & 10 & \\
Vim & 5 & 2 & \\
GPi & 6 & & \\
GPi+Vim & 2 & & \\
CM-Pf+VPL & 1 & & \\
\hline
\end{tabular}

$C M-P f$, centromedian-parafascicular complex; $D B S$, deep brain stimulation; $E T$, essential tremor; $G P i$, globus pallidus internus; $N O A C$, novel oral anticoagulants; $P D$, Parkinson disease; $S T N$, subthalamic nucleus; $V i m$, ventral intermediate nucleus; $V P L$, ventral posterior lateral nucleus 
Table 2 Chronic antiplatelet or anticoagulant treatment in 34 DBS patients

\begin{tabular}{llll}
\hline & $\begin{array}{l}\text { Antiplatelet } \\
\text { drugs }\end{array}$ & $\begin{array}{l}\text { Vitamin K } \\
\text { antagonists }\end{array}$ & NOACs \\
\hline Cardiac diseases & & & \\
$\quad$ Atrial fibrillation & 4 & 6 & 3 \\
$\quad$ Coronary artery disease & 9 & - & - \\
$\quad$ Mechanical valve & - & 3 & - \\
Cerebrovascular disorders & & & - \\
$\quad$ Previous stroke & 4 & 2 & - \\
$\quad$ Carotid stenosis & 2 & 1 & \\
Factor V thrombophilia & - & 2 & \\
\hline
\end{tabular}

Treatment had been established by the patients' general physician, internists, or cardiologists. Three patients had multiple disorders and required combined treatment $(n=37)$

$\mathrm{K}$ antagonists, and 3 had NOACs. Demographical data, diagnoses, and DBS targets are shown in Table 1.

The group of patients with long-term antiplatelet therapy consisted of 18 patients ( 12 men, 6 women, mean age $67.1 \pm 10.3$ years). The indications for DBS were as follows: PD (7 patients) - 4 bilateral STN, 1 bilateral Vim, 2 bilateral GPi; essential tremor (ET) (5 patients)—4 bilateral ventral intermediate (Vim) thalamic nucleus, 1 unilateral Vim + GPi; dystonia (5 patients) — 4 bilateral GPi, 1 bilateral GPi + Vim; and chronic pain (1 patient)—unilateral centromedian-parafascicular complex (CM-Pf) and ventral posterior lateral (VPL) nucleus.

The group of patients with vitamin $\mathrm{K}$ antagonist therapy consisted of 13 patients ( 10 men, 3 women, mean age 67.6 \pm 13.6$)$. The indications for DBS were PD (1 patient)-bilateral STN; ET (10 patients)-10 bilateral Vim; dystonia (2 patients) - 2 bilateral GPi. In the NOAC medication subgroup, there were 3 patients (2 men, 1 woman, mean age $76 \pm 2.8$ years). The indications for DBS were PD (1 patient)—bilateral Vim; and ET (2 patients)—2 bilateral Vim.

The most common indications for chronic antiplatelet or anticoagulation treatment were atrial fibrillation and coronary artery disease. Details are shown in Table 2 . Three patients had multiple diagnoses which required combined treatment.

There were no intraoperative adverse events or complications, except in one patient who suffered from mild intraoperative air embolism with coughing, but without dyspnea or hemodynamic instability.

The postoperative stereotactic CT scan detected primary asymptomatic hemorrhage in $2 / 34$ patients (5.9\%). A 74-year-old man with tremor-dominant PD and long-term treatment with apixaban because of atrial fibrillation had an intraventricular hemorrhage associated with a transventricular electrode in the postoperative CT. After four asymptomatic days, his condition worsened due to hydrocephalus, requiring an external ventricular drainage for 5 days. At 3-month follow-up, hydrocephalus was no longer present and the tremor was remarkably improved under chronic DBS. A 39-year-old woman with unilateral tremor and aspirin prophylaxis because of a previous stroke had a small, asymptomatic intracerebral bleeding along the electrode trajectory in the postoperative CT scan. There were no longterm consequences.

The number of intracranial hemorrhages on the postoperative CT scan in patients without chronic antiplatelet or anticoagulation treatment was $15 / 431(3.5 \%)$ which was not significantly different from the study group $(p=0.36$, see Table 3).

Arterial hypertension was present in 16/34 (47.1\%) of patients on chronic antiplatelet or anticoagulation treatment, and in 77/432 (17.9\%) without. Intracranial hemorrhage occurred only in $2 / 93$ patients with arterial hypertension (2.2\%) and did not present as an independent risk factor in our series.

IPG pocket hematomas occurred in 2/34 patients (5.9\%) in the group of patients on chronic antiplatelet or anticoagulation treatment. These patients had chronic medication with vitamin $\mathrm{K}$ antagonists. In the group of patients without antiplatelet or anticoagulation treatment, there were 4/421 (1\%) IPG pocket hematomas. Note that 10 patients were excluded from this analysis as they either had radiofrequency lesions

Table 3 Intracranial hemorrhage, IPG pocket hematoma, and thromboembolic complications in patients without or on chronic antiplatelet or anticoagulation treatment

\begin{tabular}{|c|c|c|c|}
\hline & $\begin{array}{l}\text { Chronic antiplatelet or anticoagula- } \\
\text { tion treatment } \\
(n=34)\end{array}$ & $\begin{array}{l}\text { No chronic antiplatelet or anticoagu- } \\
\text { lation treatment } \\
(n=431)\end{array}$ & Statistical significance \\
\hline Intracranial hemorrhage & $2(5.9 \%)$ & $15(3.5 \%)$ & \\
\hline No intracranial hemorrhage & $32(94.1 \%)$ & $416(96.5 \%)$ & n.s. $(p=.36)$ \\
\hline IPG pocket hematoma & $2(5.9 \%)$ & $4(1 \%)$ & \\
\hline No IPG pocket hematoma & $32(94.1 \%)$ & $417(99 \%)$ & n.s. $(p=.07)$ \\
\hline Thromboembolic complication & $0(0 \%)$ & $2(0.5 \%)$ & \\
\hline No thromboembolic complication & $34(100 \%)$ & $429(99.5 \%)$ & n.s. $(p=1)$ \\
\hline
\end{tabular}


or no IPG was implanted. When comparing the two groups, there was no statistical significance ( $p=0.07$, see Table 3 ).

No thromboembolic or thrombotic complications occurred in patients on antiplatelet or anticoagulation treatment during the 30-day postoperative period, while such complications were noticed, however, in 2/431 patients $(0.5 \%)$ who were not on chronic treatment.

During follow-up until 12 months after surgery, no additional thromboembolic or thrombotic or hemorrhagic complications occurred in the 34 patients on chronic antiplatelet or anticoagulation treatment. In particular, there were no instances of chronic subdural hematoma.

\section{Discussion}

DBS surgery has become a widespread and accepted therapy worldwide with an estimate of more than 180,000 patients that have been operated [19]. Along with its application to new indications, in particular considering psychiatric disorders [19], there is also a continuous process of reevaluation of what should be considered a relative contraindication for DBS. While decades ago, for example, very young age or advanced age was considered red flags, there are now published studies on DBS for childhood dystonia in infants [37] or ET in geriatric patients [16]. Moreover, psychiatric disorders and dementia, formerly considered contraindications for DBS surgery, have now increasingly moved into focus [19]. Another example is the concomitant use of cardiac pacemakers and DBS neurostimulation systems. While initially it was thought that the risk of a concomitant use would be prohibitive, this practice has become accepted over the years given certain precautions being taken [10, 15].

In the present study, we show that DBS can be performed in patients on various forms of chronic antiplatelet or anticoagulation treatment with a reasonable risk/safety profile. We did not find an increased occurrence of hemorrhagic or thromboembolic/thrombotic complications after stopping treatment and providing perioperative bridging therapy, when indicated, in comparison to patients without chronic antiplatelet or anticoagulation treatment and between different types of drugs. The management of prophylactic treatment in the perioperative phase basically was in line with the proceedings used in other neurosurgical operations. There was also no increase of chronic hemorrhagic complications such as the development of subdural hematoma for up to 1-year follow-up.

The only patient who had a symptomatic hemorrhage in our present series was operated via a transventricular approach. There is disagreement whether such an approach might constitute per se an increased risk for hemorrhage or not $[18,26,40]$.
The subject of our study has received only little attention thus far, despite the increasing age in the population and a more frequent use of antiplatelet or anticoagulant therapy [2]. In a previous study on 143 patients undergoing DBS surgery, no increased risk for intracranial hemorrhage was detected in 23 patients with previous use of anticoagulant medication [29]. The risk of IPG pocket hematoma and the occurrence of thromboembolic complications, however, were not evaluated and there was no differentiation between different forms of antiplatelet or anticoagulant therapies. Another study showed that postoperative prophylaxis with or without subcutaneous heparin for venous thromboembolism did not increase the risk for intracranial hemorrhage significantly [5]. More detailed analysis of the handling of chronic anticoagulation treatment in patients undergoing DBS or with existing DBS systems has been provided mainly in the form of case report or small case series [4, $25,31,33,39]$. We have reported previously on a patient who received bilateral pallidal DBS for severe chorea due to antiphospholipid antibody syndrome with a need for chronic phenprocoumon treatment. There were no complications of combined treatment at 2-year follow-up. In a series of 4 patients with DBS and chronic anticoagulation treatment, one IPG pocket hematoma occurred, but no intracranial hemorrhage [4].

The overall safety of DBS surgery in patients on chronic anticlotting therapy was also demonstrated in a recent study on a series of 226 patients of whom 90 patients were on chronic anticoagulation. There was no difference in adverse events between patients on anticlotting medication as compared to those without. Similarly like in our study, anticlotting treatment was paused before surgery, and a bridging protocol was installed when needed. Three hemorrhages occurred in the group who did not have chronic anticlotting treatment, and there was no instance of thromboembolic events within 90 days after surgery.

Intracranial hemorrhage in patients with DBS and subsequent anticoagulation therapy was reported very rarely. In one patient, high-dose intravenous heparin was administered on the first postoperative day for acute myocardial infarction [25], and in two other patients, edoxaban was restarted already on day 5 and day 7 after surgery [20,33]. One of these patients also had a recurrent hemorrhage later. Delayed hemorrhage occurring 9 weeks after DBS surgery was described in a patient taking low dose aspirin, but this patient suffered also from arterial hypertension [39].

The incidence of IPG pocket hematoma was remarkably low in our study, although it was higher in patients on chronic antiplatelet or anticoagulation treatment than in those without. In this context, it is also of interest to review the practice of cardiac pacemaker surgery. One study showed that continued anticoagulation therapy with warfarin in pacemaker or defibrillator surgery actually reduced the incidence of clinically 
significant IPG pocket hematoma as compared to bridging therapy with subcutaneous heparin [6]. Another large prospective study on perioperative bridging of anticoagulation treatment with vitamin $\mathrm{K}$ antagonists in patients with atrial fibrillation showed that complete pausing of anticoagulation was noninferior to perioperative bridging with low molecular weight heparin for the prevention of thromboembolic complications and that it decreased the risk of major bleeding without causing more thromboembolic complications [12].

\section{Conclusion}

We demonstrate the feasibility of implanting DBS systems in selected patients on chronic antiplatelet or anticoagulation treatment when taking certain precautions and we confirm its safety and efficiency over a follow-up period of 1 year.

Acknowledgements We would like to thank Hans E. Heissler for his expert support in statistics.

Author contribution Conception and design: Krauss, Saryyeva. Acquisition of data: Runge, Cassini Ascencao, Kinfe, Blahak, Wolf, Saryyeva, Krauss. Analysis and interpretation of data: Runge, Cassini Ascencao, Saryyeva, Krauss. Drafting the article: Runge, Cassini Ascencao, Krauss. Critically revising the article: all authors. Reviewed submitted version of manuscript: all authors. Statistical analysis: Runge, Cassini Ascencao.

Funding Open Access funding enabled and organized by Projekt DEAL.

\section{Declarations}

Ethical approval All procedures performed in studies involving human participants were in accordance with the ethical standards of the institutional and/or national research committee and with the 1964 Helsinki declaration and its later amendments or comparable ethical standards. The Ethical Commission of Hannover Medical School indicated further that no formal approval was needed for the present study.

Informed consent Informed consent was obtained from all individual participants included in the study.

Conflict of interest Luisa Cassini Ascencao: received travel grants from Medtronic; Joachim Runge: received travel grants from Medtronic; Christian Blahak: received travel grants from Ipsen; Thomas M. Kinfe: is a consultant to Medtronic and to Abbott; Christoph Schrader: none; Marc E. Wolf: none; Assel Saryyeva: received travel grants from Medtronic; Joachim K. Krauss: is a consultant to Medtronic and to Boston Scientific.

Open Access This article is licensed under a Creative Commons Attribution 4.0 International License, which permits use, sharing, adaptation, distribution and reproduction in any medium or format, as long as you give appropriate credit to the original author(s) and the source, provide a link to the Creative Commons licence, and indicate if changes were made. The images or other third party material in this article are included in the article's Creative Commons licence, unless indicated otherwise in a credit line to the material. If material is not included in the article's Creative Commons licence and your intended use is not permitted by statutory regulation or exceeds the permitted use, you will need to obtain permission directly from the copyright holder. To view a copy of this licence, visit http://creativecommons.org/licenses/by/4.0/.

\section{References}

1. Alam M, Sanghera MK, Schwabe K, Lütjens G, Jin X, Song J, Wrangel C, Stewart RM, Jankovic J, Grossman RG, Darbin O, Krauss JK (2016) Globus pallidus internus neuronal activity: a comparative study of linear and non-linear features in patients with dystonia or Parkinson's disease. J Neural Transm (Vienna) 123:231-240

2. Altiok E, Marx N (2018) Oral anticoagulation. Dtsch Arztebl Int 115:776-783

3. Amin AG, Ng J, Hsu W, Pradilla G, Raza S, Quinones-Hinojosa LM (2013) Postoperative anticoagulation in patients with mechanical heart valves following surgical treatment of subdural hematomas. Neurocrit Care 19:90-94

4. Ashkan K, Alamri A, Ughratdar I (2015) Anticoagulation and deep brain stimulation: never the twain shall meet? Stereotact Funct Neurosurg 93:373-377

5. Baumann JA, Church E, Halpern CH, Danish SF, Zaghloul KA, Jaggi JL, Stein SC, Baltuch GH (2009) Subcutaneous heparin for prophylaxis of venous thromboembolism in deep brain stimulation surgery: evidence from a decision analysis. Neurosurgery 65:276-280

6. Birnie DH, Healey JS, Wells GA, Verma A, Tang AS, Krahn AD, Simpson CS, Ayala-Paredes F, Coutu B, Leiria TLL, Vidal Essebag V (2013) Pacemaker or defibrillator surgery without interruption of anticoagulation. N Engl J Med 368:2084-2089

7. Blahak C, Wöhrle JC, Capelle HH, Bäzner HJ, Grips E, Weigel R, Hennerici MG, Krauss JK (2007) Tremor reduction by subthalamic nucleus stimulation and medication in advanced Parkinson's disease. J Neurol 254:169-178

8. Butchart EG, Gohlke-Bärwolf C, Antunes MJ, Tornos P, De Caterina R, Cormier B, Prendergast B, Iung B, Bjornstad H, Leport C, Hall RJC, Vahanian A (2005) Recommendations for the management of patients after heart valve surgery. Eur Heart $J$ 26:2463-3247

9. Capelle HH, Blahak C, Schrader C, Bäzner H, Kinfe TM, Herzog J, Dengler R, Krauss JK (2010) Chronic deep brain stimulation in patients with tardive dystonia without a history of major psychosis. Mov Disord 25:1477-1481

10. Capelle HH, Simpson RK, Kronenbuerger M, Michaelsen J, Tronnier V, Krauss JK (2005) Long-term deep brain stimulation in elderly patients with cardiac pacemakers. J Neurosurg 102:53-59

11. Deer TR, Narouze S, Provenzano DA, Pope JE, Falowski SM, Russo MA, Benzon H, Slavin K, Pilitsis JG, Alo K, Carlson JD, McRoberts P, Lad SP, Arle J, Levy RM, Simpson B, Mekhail N (2017) The Neurostimulation Appropriateness Consensus Committee (NACC): recommendations on bleeding and coagulation management in neurostimulation devices. Neuromodulation 20:51-62

12. Douketis JD, Spyropoulos AC, Kaatz S, Becker RC, Caprini JA, Dunn AS, Garcia DA, Jacobson A, Jaffer AK, Kong DF, Schulman S, Turpie AGG, Hasselblad V, Ortel TL (2015) Perioperative bridging anticoagulation in patients with atrial fibrilation. N Engl J Med 373:823-833

13. El Ahmadieh TY, Aoun SG, Daou MR, El Tecle NE, Ràhme RJ, Graham RB, Adel JG, Batjer HH, Bendok BR (2013) 
New-generation oral anticoagulants for the prevention of stroke: implications for neurosurgery. J Clin Neurosci 20:1350-1356

14. Fasano A, Aquino CC, Krauss JK, Honey CR, Bloem BR (2015) Axial disability and deep brain stimulation in patients with Parkinson's disease. Nat Rev Neurol 11:98-110

15. Heard T, Coyne T, Silburn P (2019) Deep brain stimulation in patients with concomitant cardiac pacemakers: a case series. Oper Neurosurg (Hagerstown) 17:549-553

16. Klein J, Büntjen L, Jacobi G, Galazky I, Panther P, Zaehle T, Kaufmann J, Heinze HJ, Voges J, Kupsch A (2017) Bilateral thalamic deep brain stimulation for essential tremor in elderly patients. J Neural Transm (Vienna) 124:1093-1096

17. Krack P, Volkmann J, Tinkhauser G, Deuschl G (2019) Deep brain stimulation in movement disorders: from experimental surgery to evidence-based therapy. Mov Disord 34:1795-1810

18. Kramer DR, Halpern CH, Danish SF, Jaggi JL, Baltuch GH (2012) The effect of intraventricular trajectory on brain shift in deep brain stimulation. Stereotact Funct Neurosurg 90:20-34

19. Lozano AM, Lipsman N, Bergman H, Brown P, Chabardes S, Chang JW, Matthews K, McIntyre CC, Schlaepfer TE, Schulder M, Temel Y, Volkmann J, Krauss JK (2019) Deep brain stimulation: current challenges and future directions. Nat Rev Neurol $15: 148-160$

20. Martin AJ, Starr PA, Ostrem JL, Larson PS (2017) Hemorrhage detection and incidence during magnetic resonance-guided deep brain stimulator implantations. Stereotact Funct Neurosurg 95:307-314

21. Mirzayan MJ, Calvelli K, Capelle HH, Weigand J, Krauss JK (2016) Subdural hematoma and oral anticoagulation: a therapeutic dilemma from the neurosurgical point of view. J Neurol Surg A Cent Eur Neurosurg 77:31-35

22. Mitchell KT, Ostrem JL (2020) Surgical treatment of Parkinson disease. Neurol Clin 38:293-307

23. Nowak-Göttl U, Langer F, Limperger V, Mesters R, Trappe RU (2014) Bridging: perioperative management of chronic anticoagulation or antiplatelet therapy. Dtsch Med Wochenschr 139:1301-1306

24. Patel DM, Walker HC, Brooks R, Omar N, Ditty B, Guthrie BL (2015) Adverse events associated with deep brain stimulation for movement disorders: analysis of 510 consecutive cases. Neurosurgery 11(Suppl 2):190-199

25. Polanski W, Koy J, Juratli T, Wolz M, Klingelhöfer L, Fauser M, Storch A, Schackert G, Sobottka SB (2013) Anticoagulation management of myocardial infarction after deep brain stimulation: a comparison of two cases. Acta Neurochir (Wien) 155:1661-1665

26. Ray K, Bernstein J, Kashyap S, Ananda A (2019) Safety of the transventricular approach to deep brain stimulation: a retrospective review. Surg Neurol Int 10:192

27. Reese R, Gruber D, Schoenecker T, Bäzner H, Blahak C, Capelle HH, Falk D, Herzog J, Pinsker MO, Schneider GH, Schrader C, Deuschl G, Mehdorn HM, Kupsch A, Volkmann J, Krauss JK (2011) Long-term clinical outcome in Meige syndrome treated with internal pallidum deep brain stimulation. Mov Disord 26:691-698

28. Reich MM, Horn A, Lange F, Roothans J, Paschen S, Runge J, Wodarg F, Pozzi NG, Witt K, Nickl RC, Soussand L, Ewert S, Maltese V, Wittstock M, Schneider GH, Coenen V, Mahlknecht P, Poewe W, Eisner W, Helmers AK, Matthies C, Sturm V, Isaias IU, Krauss JK, Kühn AA, Deuschl G, Volkmann J (2019) Probabilistic mapping of the antidystonic effect of pallidal neurostimulation: a multicentre imaging study. Brain 142:1386-1398
29. Sansur CA, Frysinger RC, Pouratian N, Fu KM, Bittl M, Oskouian RJ, Laws ER, Elias WJ (2007) Incidence of symptomatic hemorrhage after stereotactic electrode placement. J Neurosurg 107:998-1003

30. Schepers IM, Beck AK, Bräuer S, Schwabe K, Abdallat M, Sandmann P, Dengler R, Rieger JW, Krauss JK (2017) Human centromedian-parafascicular complex (CM-Pf) signals sensory cues for goal-oriented behavior selection. Neuroimage 152:390-399

31. Schrader C, Aumüller M, Lütjens G, Saryyeva A, Capelle HH, Krauss JK (2015) Bilateral pallidal stimulation improves chorea in antiphospholipid antibody syndrome with oral anticoagulation. Mov Disord Clin Pract 2:194-196

32. Schrader C, Capelle HH, Kinfe TM, Blahak C, Bäzner H, Lütjens DD, Krauss JK (2011) GPi-DBS may induce a hypokinetic gait disorder with freezing of gait in patients with dystonia. Neurology 77:483-488

33. Sivakumar W, Garber ST, Schrock LE, House PA (2013) Recurrent, delayed hemorrhage associated with edoxaban after deep brain stimulation lead placement. Case Rep Neurol Med 2013:691840

34. Skardelly M, Mönch L, Order C, Hockel K, Tatagiba MS, Ebner FH (2018) Survey of the management of perioperative bridging of anticoagulation and antiplatelet therapy in neurosurgery. Acta Neurochir (Wien) 160:2077-2085

35. Terao T, Takahashi H, Yokochi F, Taniguchi M, Okiyama R, Hamada I (2003) Hemorrhagic complication of stereotactic surgery in patients with movement disorders. J Neurosurg 98:1241-1246

36. Topp G, Ghulam-Jefani Z, Chockalingam A, Kumar V, Byraju K, Sukul V, Pilitsis JG (2021) Safety of deep brain stimulation lead placement on patients requiring anticlotting therapie. World Neurosurg 145:e320-e325

37. Tustin K, Elze MC, Lumsden DE, Gimeno H, Kaminska M, Lin JP (2019) Gross motor function outcomes following deep brain stimulation for childhood-onset dystonia: a descriptive report. Eur J Paediatr Neurol 23:473-483

38. Voges J, Hilker R, Bötzel K, Kiening KL, Kloss M, Kupsch A, Schnitzler A, Schneider GH, Steude U, Deuschl G, Pinsker MO (2007) Thirty days complication rate following surgery performed for deep-brain-stimulation. Mov Disord 22:1486-1489

39. Zesiewicz TA, Sullivan KL, Hoffmann M, Benes LM, Smith DA, Ward CL, Hauser RA (2008) Delayed thalamic intracranial hemorrhage in an essential tremor patient following deep brain stimulation. Eur Neurol 59:187-189

40. Zrinzo L, Foltynie T, Limousin P, Hariz MI (2012) Reducing hemorrhagic complications in functional neurosurgery: a large case series and systematic literature review. J Neurosurg 116:84-94

Publisher's note Springer Nature remains neutral with regard to jurisdictional claims in published maps and institutional affiliations.

Comments Straightforward description of the preoperative/ periroperative management of antiplatelet and anticoagulation treatments in patients receiving DBS surgery. Feasibility of the procedure in selective patients is documented with no significant increase of risk for both, intracranial hemorrhage and implantable pulse generator pocket hematomas.

Ana-Laura Cif.

Montpellier, France 